\title{
Craniocerebral gunshot injuries in preschoolers
}

\author{
Furqan B. Irfan - Rameez UI Hassan • Rajesh Kumar • \\ Zain Ali Bhutta $\cdot$ Ehsan Bari
}

Received: 21 July 2009/Published online: 9 September 2009

(C) Springer-Verlag 2009 four patients, three presented with GCS between 3 and 5 while 1 presented with GCS well above ten.

Conclusion Our results show that even in children presenting with low GCS $<5$, an early act of aggressive surgical intervention can prove to be a life-saving measure.

Keywords Firearm · Children · Trauma · Neurosurgery · Intraventricular hemmorrhage $\cdot$ Brain

\section{Introduction}

Gunshots to the head in children are being encountered with increasing frequency [1-3]. Among gunshot head wounds, children with such injuries form an important subset as outcomes and prognosis differ when compared with adults [1, 2, 4-7]. Even the mode of injury, transit time, entrance wound site, and region of brain primarily affected differ significantly when compared with adult population of gunshot wounds (GSW) to the head [6]. However, the most striking difference between children and adults with craniocerebral GSW is the difference in age-related morbidity [6, 8]. Gunshot head wounds in children who survive lead to neurobehavioral and neuropsychological deficits which vary according to the developmental level and age at the time of GSW injury [8].

Despite the alarming increased incidence and morbidity of GSW to the head in children, very few studies have been published on this topic [2]. Moreover, the clinical and outcome data on specific age groups of children with craniocerebral GSW are further lacking $[6,8]$. To our knowledge, there is no study solely devoted to craniocerebral GSW in very young children less than 5 years of age, although there are a few studies which have included this subgroup as part of a wider age-group of children $[6,8]$. We report four children from 2 to 3 years of age presenting to a
Department of Neurosurgery, Aga Khan University, Stadium Road, P.O. Box 3500, Karachi 74800 Sindh, Pakistan e-mail: rajesh.kumar@aku.edu 
tertiary healthcare center with craniocerebral GSW and review the current literature.

\section{Case reports}

At arrival in the emergency room (ER), all four children with GSW were resuscitated with fluids (crystalloids and colloids), endotracheally intubated, and mechanically ventilated. Patients were ventilated and received mannitol/ hypertonic saline to lower intracranial pressure along with prophylactic anticonvulsants and antibiotics. After achieving hemodynamic stability, computed tomographic (CT) brain scans were taken, and all four children were rushed to the operating room (OR). Postoperatively, patients were shifted to the pediatric intensive care unit, sedated, and given muscle relaxant and morphine for analgesia. Patients also received inotropes, and electrolyte and metabolic derangements were corrected accordingly.

The admission Glasgow Coma Scale (GCS), complications, and Glasgow Outcome Scale (GOS) scores for all patients are given in Table 1.

\section{Patient 1}

A girl aged 2 years and 9 months was hit on the head by a stray bullet while riding on a motorcycle with her uncle. She presented to the ER one and a half hours after the incident with unstable vital signs, anisocoric pupils (left fixed and dilated), and GCS of 5/15. The entrance wound was on the vertex of the head. CT brain scan revealed left basal ganglion and intraventricular hemorrhage and ventricular effacement due to mass effect (Fig. 1a) along with pneumocranium and a bullet lodged at the skull base (Fig. 1b). She was taken to the OR $80 \mathrm{~min}$ after presentation, and a bifrontal decompressive craniotomy with entry-wound debridement and duraplasty was performed. There was no attempt to remove the bullet lodged at base of skull (Fig. 1c).

Postoperatively, there was no improvement in her condition; her left pupil remained fixed and dilated; her GCS dropped to $3 / 15$, and there was no neurological response even after holding sedatives for $24 \mathrm{~h}$. A CT brain scan the next day revealed development of multiple infarcts with increase in intraventricular hemorrhage and associated midline shift. The condition deteriorated, and there was absence of brainstem reflexes. Inotropic and ventilator support was withdrawn, and the patient passed away 3 days after the incident.

\section{Patient 2}

A boy aged 2 years and 6 months was brought to the ER unconscious and bleeding profusely from GSW to left frontoparietal region of his head while the exit wound was from right temporal region. The child was shot accidentally around $1 \mathrm{~h}$ prior to presentation when his father was shot by dacoits. On examination, vital signs were unstable; pupils were bilaterally equal and responsive to light, and his Glasgow coma scale score was 4/15. A CT brain scan revealed parenchymal and subarachnoid hemorrhage associated with pneumocranium and multiple bullet pellets in bilateral frontal lobes. The child was taken to the operating room $80 \mathrm{~min}$ after presenting to the ER. The entry and exit wounds were debrided. Left frontoparietal decompressive craniotomy with debridement and duraplasty was performed.

On assessment the next day, the child was not moving the right side of his body, and the CT scan revealed left middle cerebral artery infarct. Over the next couple of days, the child improved gradually with withdrawal to pain from right side of his limbs and was extubated on day 5. On day 11, the child was discharged alert and playful with persisting right-sided weakness.

On follow-up after a week, his right-sided hemiparesis was better (grade 2-3), and on consecutive weekly and fortnightly follow-ups, he improved neurologically (hemiparesis, speech, and neck-holding improved).

He underwent cranioplasty after 2 months. On successive follow-ups, right hemiparesis, activity, and speech improved with no signs of neurological irritability. On last follow-up, after 14 months, there was right hemiparesis, but the child could walk and run independently and could speak few words.

Table 1 Patients' admission Glasgow Coma Scale (GCS), complications, and Glasgow Outcome Scale (GOS)

\begin{tabular}{|c|c|c|c|c|}
\hline & $\begin{array}{l}\text { Admission Glasgow Coma } \\
\text { Scale (GCS) }\end{array}$ & Postoperative complication & $\begin{array}{l}\text { Long-term } \\
\text { complication }\end{array}$ & $\begin{array}{l}\text { Glasgow Outcome } \\
\text { Scale (GOS) }\end{array}$ \\
\hline Patient 1 & 5 & Death & - & 1 \\
\hline Patient 2 & 4 & $\begin{array}{l}\text { Subgaleal fluid collection } \\
\text { Hemiparesis }\end{array}$ & $\begin{array}{l}\text { Hemiparesis } \\
\text { Hydrocephalus }\end{array}$ & 4 \\
\hline Patient 3 & 4 & Seizures & - & 5 \\
\hline Patient 4 & 14 & - & Lost to follow-up & 5 \\
\hline
\end{tabular}



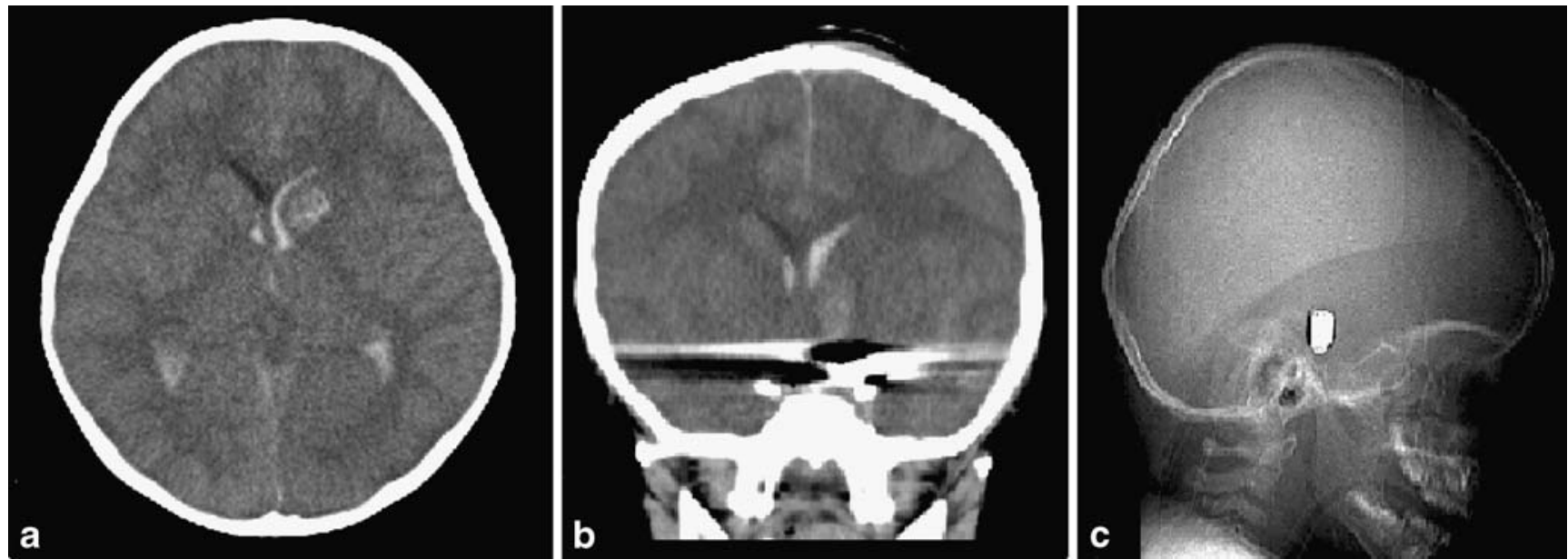

Fig. 1 a CT brain scan axial view. b CT brain scan coronal view showing the trajectory of bullet. c X-ray skull lateral view showing the lodged bullet at skull base

\section{Patient 3}

A 3-year-old girl, with a history of GSW to the head by dacoits, was transferred from a secondary care center after initial resuscitation and tracheal intubation to our institution approximately $2 \mathrm{~h}$ after the gunshot injury. Her vital signs were unstable, and there was no air entry on the left side of the chest; the child was reintubated. The entrance wound was on the left parietal region while brain matter was extricating from the exit wound on the right parietal region. Pupils were equal and responsive to light, and her Glasgow Coma Scale score was $4 / 15$. CT brain scan revealed intraparenchymal and subdural hemorrhage with multiple pellets and bony pieces, associated pneumocephalus, and temporal bone fracture (Fig. 2a, b). Within $50 \mathrm{~min}$, the child was rushed to the operating room where bilateral left parietal and right parietal craniotomies (Fig. 2c, d), wound debridement, and duraplasty were performed.

Postoperatively, her condition improved gradually, and she was discharged alert and responsive on day 11. On successive follow-ups, the child was alert and playful and moving all limbs. CT scan brain revealed an infarct in the bullet tract bilaterally in the parietal region with no evidence of hydrocephalus. She underwent bilateral cranioplasty after one and a half month. On last follow-up after 4 months, the child was improving with no signs of any significant neurological deficit.

\section{Patient 4}

A 3-year-old boy was brought to the ER $12 \mathrm{~h}$ after receiving a GSW to the head while playing in the backyard. His mother tried to stem the flow of blood by applying cold packs and tea leaves, but bleeding continued, and the child was taken to a secondary care health center where the doctor cleaned and stitched the wound. The child was fully conscious and oriented, but despite the stitch, the wound kept bleeding, and the child developed a left black eye. On arrival at our center, the child was vitally stable with GCS score of $14 / 15$ with the entrance wound over the right frontoparietal region and a left periorbital hematoma. The pupil on the right side was normal and reactive while the left pupil was difficult to visualize because of swelling. CT scan revealed gunshot injury involving both frontal lobes; the bullet had traveled from the right frontal region to the roof of the orbit and was lying under the frontoparietal region on the left side. A left frontoparietal craniotomy was performed the next day. The bullet was removed, the hematoma, aspirated, and some necrotic brain, removed. The dura was repaired, and the bone flap replaced.

Postoperatively, the child woke up with GCS score of $15 / 15$ and no neurological deficit. However, swelling and ecchymosis of the left eye had increased, along with weakness of extraocular muscles. The child remained in the hospital for a further 1 week during which his periorbital hematoma decreased, and there was no loss of vision. He was lost to follow-up.

\section{Discussion}

Children under the age of 4 years and adolescents from 15 to 19 years of age are the two age groups at highest risk for traumatic brain injury [9]. Assaults account for nearly 4\% of the cases of traumatic brain injury in children with firearms being a leading cause [9]. Previous studies, especially from developed countries have mainly concentrated on craniocerebral GSW in older-age group of children and adolescents, often in relation to distribution of drugs and gang-related homicides $[6,10]$. 
Fig. 2 a CT scan axial view showing bullet tract. b CT scan coronal view showing bullet tract and fracture of right parietal bone. c CT scan axial view postoperatively, showing right parietal craniotomy with brain herniation and cerebral edema. $\mathbf{d}$ CT scan axial view postoperatively, showing left parietal craniotomy with herniated brain
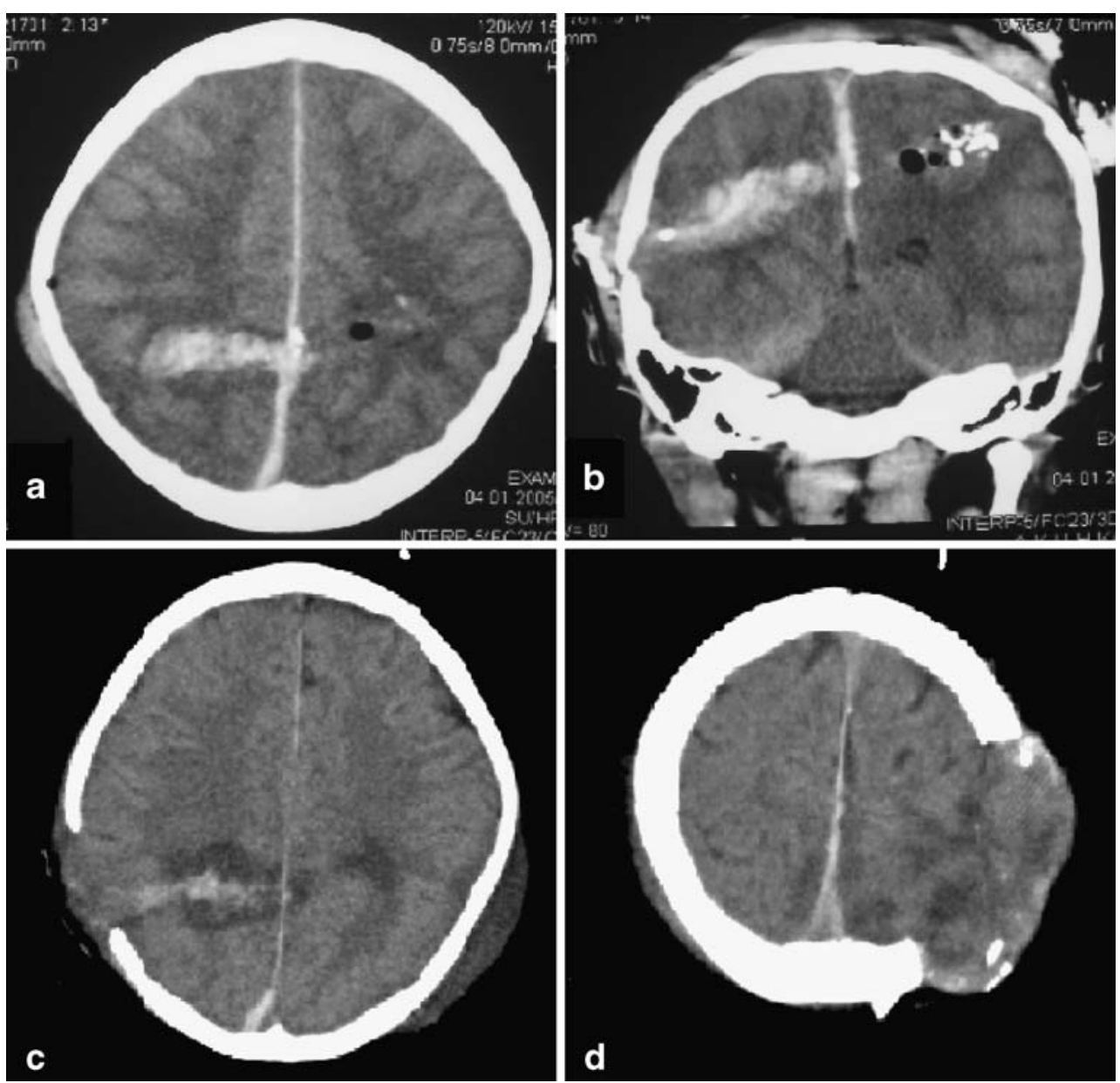

Majority of similar studies which have included children less than 3 years of age with craniocerebral GSW as part of their larger study have, more or less, comparable numbers of patients as our study, in this age group [1, 3, 8, 11].

In our series, all patients were very young children who received craniocrebral GSW accidentally or in crossfire where they were not the intended primary targets. This is consistent with other studies carried out which include younger children with craniocerebral GSW where children "caught in crossfire" and accidental GSW accounted for $73 \%$ of the cases [1]. Such incidents of GSW are directly related to the prevailing levels of violence. As in the last few years, lawlessness and the scourge of terrorism and religious extremism in this part of the world have increased $[12,13]$; cases of craniocerebral GSW will undoubtedly increase. This is also evident from our patient records as our first case was in 1991 compared with three such cases in 2008 .

Admission or presenting GCS in craniocerebral GSW has been found to be an important predictor of outcome with mortality nearly $95 \%$ when presenting GCS score is under 5 [3, 4, 14-17]. However, of the three children in our series who were admitted with low GCS of 3-5 (Table 1), only one out of the three did not survive. Compared with other studies where presenting GCS scores of less than 4-5 in children with craniocerebral GSW that led mostly to death [3, 11], our results are good. A study by EwingCobbs et al. (1994) also reported low mortality rates in children with craniocerebral GSW with initial GCS score of 3-5 [8].

The initial CT brain scan findings in our patients included intraventricular hemorrhage in one patient and bihemispheric multilobar injury in three patients; both features have been correlated with poor outcomes [6]. Among intracranial hemorrhages, intraventricular hemorrhage is the most important and signifies ventricular injury leading to worse prognosis even in the absence of ventricular penetration [18-20]. This is consistent with our report on patient 1 , who had intraventricular hemorrhage and did not survive. Multiple lobe involvement also affects prognosis with a study reporting $88.9 \%$ survival in single lobe involvement versus $54.2 \%$ survival when more than one lobe is involved [16]. The outcome worsens further when multilobe involvement is bihemispheric with $15 \%$ to $17 \%$ survival reported [4, 17]. However, all our three patients with bihemispheric multilobar injuries sur- 
vived. This is consistent with results in a similar study in which only one of five children with bihemispheric multilobe injury died, in contrast to worse outcomes in adults with such injuries [1].

Our results, particularly with bihemispheric multilobe injuries, lend credence to the notion that mortality from GSW to the head is lower in younger patients [1]. On the other hand, Levy et al. (1993) reported decreasing mortality in craniocerebral GSW with increasing age [6]. Another study found no difference in mortality with age in patients with GSW to the head [3].

Three of our patients had admitting GCS scores of 3-5 (Table 1), and there is controversy in literature about aggressive surgical management in such patients with very low GCS scores. Some studies have advocated no role of surgery in patients with GCS of 3-5 with or without fixed pupils $[5,15,17,18,21]$. However, other studies have recommended surgery even in patients with a GCS score of 3 , as surgical treatment can lead to occasional recoveries [22-24]. We agree with studies advocating surgical treatment in patients with craniocerebral GSW presenting with GCS score of 3-5, in civilian setting, as we operated on all three such patients and two of them survived.

Intracranial pressure monitoring has been shown to be an important aspect of management in patients with craniocerebral GSW [11]. However, much as we realize the importance of intracranial pressure monitoring, we were unable to do so as we lacked the equipment for this purpose, our study being carried out in a third world country with limited resources. To control intracranial pressure, we adopted standard measures of endotracheal intubation, ventilation, sedatives, muscle relaxant, and mannitol/hypertonic saline [11].

The survival and functional outcomes of our patients were assessed by GOS scores [25]. As studies show that GOS scores do not change during first 3 years postinjury [8], losing patient 4, who had an initial GCS score of 15 and discharge GOS score of 5, to follow-up did not affect our results. Of three patients with initial GCS scores of 3-5, patient 1 died (GOS score of 1), patient 2 had hemiparesis (moderate disability, GOS score of 4), and patient 3 had resumption of near-normal activity (good recovery; GOS score of 5; Table 1). Our mixed results in children with GCS scores of 3-5 are not different from previous studies which all present varying results. Coughlan et al. (2003) reported GCS score of less than 4 leading to death while GCS score of 4-7 was associated mostly with death and severe disability; Ewing-Cobbs et al. (1999) found that initial GCS score of 3-5 resulted in moderate disabilities (GOS score of 4), and Paret et al. (1989) reported that GCS of 3-5 mostly led to death (GOS score of 1) [1, 3, 8].

Although this study is limited to craniocerebral gunshot wounds, traumatic brain injury in children not only due to craniocerebral GSW but also to craniocerebral blast injuries is expected to increase in this part of the world as a result of affliction of suicide bombing and bomb blasts by terrorists and religious extremists $[12,13]$. We have to reflect and make a concerted effort to tackle the ills of our society where children are being shot before they even begin to go to school.

\section{Conclusion}

In our series, two children received GSW to the head by stray bullets while the other two received them during an attempted robbery. The commonest pattern of injury was bihemispheric where the outcome was better when compared with literature on adults. Although intracranial pressure monitoring was not available, our results with initial GCS scores of 3-5 and aggressive surgical intervention were encouraging, and we support surgical intervention in such children with craniocerebral GSW presenting even with very low GCS.

\section{Acknowledgements Dr Saima Hafeez, MBBS}

Disclosure/Disclaimer The authors declare that there is no conflict of interest concerning the materials or methods used in this study or the findings specified in this paper, and there were no sources of support or funding for this study.

\section{References}

1. Coughlan MD, Fieggen AG, Semple PL, Peter JC (2003) Craniocerebral gunshot injuries in children. Childs Nerv Syst 19:348-352

2. Miner ME, Ewing-Cobbs L, Kopaniky DR, Cabrera J, Kaufmann $P$ (1990) The results of treatment of gunshot wounds to the brain in children. Neurosurgery 26:20-24 discussion 24-25

3. Paret G, Barzilai A, Lahat E, Feldman Z, Ohad G, Vardi A, BenAbraham R, Barzilay Z (1998) Gunshot wounds in brains of children: prognostic variables in mortality, course, and outcome. J Neurotrauma 15:967-972

4. Kaufman HH, Makela ME, Lee KF, Haid RW Jr, Gildenberg PL (1986) Gunshot wounds to the head: a perspective. Neurosurgery 18:689-695

5. Levy ML, Masri LS, Lavine S, Apuzzo ML (1994) Outcome prediction after penetrating craniocerebral injury in a civilian population: aggressive surgical management in patients with admission Glasgow Coma Scale scores of 3, 4, or 5. Neurosurgery 35:77-84 discussion 84-75

6. Levy ML, Masri LS, Levy KM, Johnson FL, Martin-Thomson E, Couldwell WT, McComb JG, Weiss MH, Apuzzo ML (1993) Penetrating craniocerebral injury resultant from gunshot wounds: gang-related injury in children and adolescents. Neurosurgery 33:1018-1024 discussion 1024-1015

7. Shoung HM, Sichez JP, Pertuiset B (1985) The early prognosis of craniocerebral gunshot wounds in civilian practice as an aid to the choice of treatment. A series of 56 cases studied by the computerized tomography. Acta Neurochir (Wien) 74:27-30 
8. Ewing-Cobbs L, Thompson NM, Miner ME, Fletcher JM (1994) Gunshot wounds to the brain in children and adolescents: age and neurobehavioral development. Neurosurgery 35:225-233 discussion 233

9. Langlois JA, Rutland-Brown W, Thomas KE (2004) Traumatic brain injury in the United States: emergency department visits, hospitalizations, and deaths. Centers for Disease Control and Prevention, Nation Center for Injury Prevention and Control, Atlanta (GA)

10. Barlow B, Niemirska M, Gandhi RP (1982) Ten years' experience with pediatric gunshot wounds. J Pediatr Surg 17:927-932

11. Sarnaik AP, Kopec J, Moylan P, Alvarez D, Canady A (1989) Role of aggressive intracranial pressure control in management of pediatric craniocerebral gunshot wounds with unfavorable features. J Trauma 29:1434-1437

12. Malik ZU, Hanif MS, Tariq M, Aslam R, Munir AJ, Zaidi H, Akmal M (2006) Mass casualty management after a suicidal terrorist attack on a religious procession in Quetta, Pakistan. J Coll Physicians Surg Pak 16:253-256

13. Zafar H, Rehmani R, Chawla T, Umer M, Mohsin eA (2005) Suicidal bus bombing of French nationals in Pakistan: physical injuries and management of survivors. Eur J Emerg Med 12:163167

14. Aarabi B (1990) Surgical outcome in 435 patients who sustained missile head wounds during the Iran-Iraq War. Neurosurgery 27:692-695 discussion 695

15. Grahm TW, Williams FC Jr, Harrington T, Spetzler RF (1990) Civilian gunshot wounds to the head: a prospective study. Neurosurgery 27:696-700 discussion 700
16. Kennedy F, Gonzalez P, Dang C, Fleming A, Sterling-Scott R (1993) The Glasgow Coma Scale and prognosis in gunshot wounds to the brain. J Trauma 35:75-77

17. Nagib MG, Rockswold GL, Sherman RS, Lagaard MW (1986) Civilian gunshot wounds to the brain: prognosis and management. Neurosurgery 18:533-537

18. Clark WC, Muhlbauer MS, Watridge CB, Ray MW (1986) Analysis of 76 civilian craniocerebral gunshot wounds. J Neurosurg 65:9-14

19. Siccardi D, Cavaliere R, Pau A, Lubinu F, Turtas S, Viale GL (1991) Penetrating craniocerebral missile injuries in civilians: a retrospective analysis of 314 cases. Surg Neurol 35:455-460

20. Tsai FY, Huprich JE, Gardner FC, Segall HD, Teal JS (1978) Diagnostic and prognostic implications of computed tomography of head trauma. J Comput Assist Tomogr 2:323-331

21. Dosoglu M, Orakdogen M, Somay H, Ates O, Ziyal I (1999) Civilian gunshot wounds to the head. Neurochirurgie 45:201-207

22. Kaufman HH, Loyola WP, Makela ME, Frankowski RF, Wagner KA, Bernstein DP, Gildenberg PL (1983) Civilian gunshot wounds: the limits of salvageability. Acta Neurochir (Wien) 67:115-125

23. Levi L, Borovich B, Guilburd JN, Grushkiewicz I, Lemberger A, Linn S, Schachter I, Zaaroor M, Braun J, Feinsod M (1990) Wartime neurosurgical experience in Lebanon, 1982-85. I: Penetrating craniocerebral injuries. Isr J Med Sci 26:548-554

24. Stone JL, Lichtor T, Fitzgerald LF (1995) Gunshot wounds to the head in civilian practice. Neurosurgery 37:1104-1110 discussion $1110-1102$

25. Jennett B, Bond M (1975) Assessment of outcome after severe brain damage. Lancet 1:480-484 